\title{
Risk factors for cerebral complications after type A aortic dissection surgery: single center's experience
}

\author{
Yunxing Xue $\mathrm{e}^{1,2,3 \#}$, Chang Liu ${ }^{2,3,4 \#}$, Lin $\mathrm{Mi}^{2,3}$, Yang Chen ${ }^{2,3}$, Dongjin Wang ${ }^{1,2,3,4}$ \\ ${ }^{1}$ Nanjing Drum Tower Hospital Clinical College of Nanjing Medical University, Nanjing, China; ${ }^{2}$ Department of Cardiothoracic Surgery, Nanjing \\ Drum Tower Hospital, The Affiliated Hospital of Nanjing University Medical School, Nanjing, China; ${ }^{3}$ Institute of Cardiothoracic Vascular Disease, \\ Nanjing University, Nanjing, China; ${ }^{4}$ Clinical College of Traditional Chinese and Western Medicine, Nanjing University of Chinese Medicine, \\ Nanjing, China \\ Contributions: (I) Conception and design: Y Xue; (II) Administrative support: Y Chen, D Wang; (III) Provision of study materials or patients: C Liu, L \\ Mi; (IV) Collection and assembly of data: C Liu, L Mi; (V) Data analysis and interpretation: Y Xue; (VI) Manuscript writing: All authors; (VII) Final \\ approval of manuscript: All authors. \\ \#These authors contributed equally to this work. \\ Correspondence to: Dongjin Wang, MD, PhD. 321 Zhongshan Road, Nanjing 210000, China. Email: dongjinwang_gl@163.com.
}

\begin{abstract}
Background: The objective of this study was to retrospectively review the rate and risk factors of cerebral complications (CC) after type A aortic dissection (TAAD) surgery.

Methods: A total of 746 TAAD patients who underwent hypothermic circulatory arrest (HCA) surgery were enrolled. Postoperative CC were defined as intracranial hemorrhage or ischemic infarct stroke as confirmed by cranial CT scan. Multivariable logistic regression analysis was used to investigate the risk factors for CC and mortality. To identify the risk role of arch repair methods and flow rate in antegrade cerebral perfusion (ACP), propensity-score matching studies were performed (conservative vs. total arch replacement, $\mathrm{n}=135$; low $v$ s. normal flow rate, $\mathrm{n}=148$ ).

Results: Thirty-five patients developed CC (6 with intracranial hemorrhage and 29 with ischemic stroke). Thirty-day mortality (34.3\%) among patients with CC was significantly higher than that among patients without CC (12.2\%). Multivariable logistic regression analysis identified preoperative cerebral ischemia, limb ischemia, end-stage renal disease, and salvage surgery as risk factors for postoperative CC. CAR ( $\mathrm{P}=0.044$; odds ratio, 4.587; 95\% CI: 1.045-20.130) and low flow rate ACP ( $\mathrm{P}=0.046$; odds ratio, 2.139; 95\% CI: 1.014-4.515) had protective roles. In the propensity-score matching studies, the CAR group $(0.7 \%$ and 9.6\%, $\mathrm{P}=0.005$ and 0.175 , respectively) and the low flow rate ACP group had lower rates of mortality $(8.8 \%$ and $5.4 \%, \mathrm{P}=0.067$ and 0.012 , respectively) and CC.
\end{abstract}

Conclusions: CC are common and lethal after TAAD surgery. Low-flow ACP could be a safer and suitable antegrade perfusion method for cerebral protection.

Keywords: Aortic dissection; cerebral complication; cerebral perfusion

Submitted Nov 28, 2020. Accepted for publication May 26, 2021.

doi: 10.21037/apm-20-2365

View this article at: https://dx.doi.org/10.21037/apm-20-2365

\section{Introduction}

Cerebral complications (CC) are severe postoperative complications of type A aortic dissection (TAAD) surgery. The rate of CC has been reported be as high as $10-30 \%$ and will increase the rate of mortality 2 - to 3 -fold $(1,2)$.
Previous retrospective studies found that the methods of aortic arch surgery, arterial cannulation, hypothermic strategy and cerebral perfusion were risk factors of CC (3). As results from different studies were controversial, there are no standards of cerebral protection during TAAD surgery. And no prospective randomized trial is available 
for TAAD surgery, thus we retrospective reviewed the data from our center with a large cohort to analyze the risk factors for CC after TAAD surgical repair.

We present the following article in accordance with the STROBE reporting checklist (available at https://dx.doi. org/10.21037/apm-20-2365).

\section{Methods}

\section{Patients}

From January 2010 to December 2017, 746 patients diagnosed with Stanford TAAD underwent surgery in our center. Among them, 711 patients had not developed CC (non-CC group), and 35 patients were diagnosed with CC (CC group) after surgery. Six patients had intra cranial hemorrhage, and 29 patients had ischemic infarct stroke. All patients in the CC group received head CT scans, and positive intracranial lesions were identified. CC referred to those of a focal (stroke) or global (parkinsonism, coma, gait disturbance) nature that persisted at discharge from the hospital (4).

The clinical preoperative, operative, and postoperative characteristics were collected through the electronic charts of all patients. We retrieved the data retrospectively by a review of hospital records, and individual consent for this retrospective analysis was waived. The study was conducted in accordance with the Declaration of Helsinki (as revised in 2013). The study was approved by the Institutional Review Board of Nanjing Drum Tower Hospital (No. 2020-185-01).

\section{Surgical approach}

The surgical approaches were reported in our previous articles on TAAD. We chose different methods for aortic arch repair according to the patients' anatomic indications (5-7). Partial aortic arch replacement was defined as conservative arch repair (CAR), and total arch replacement and arch stent procedures were defined as total arch repair (TAR). In a subsequent propensity-score matching analysis, the TAR group was divided into two subgroups: the Totalarch group and the Arch-stent group. Root repair was performed with the reinforcement reconstruction method as previously reported $(8,9)$. The Bentall procedure was performed as described in the literature.

\section{Cannulation and cerebral perfusion method}

The right axillary artery and femoral artery were the first choices for arterial cannulation. Based on the expected duration of the circulatory arrest and the intended surgical procedure, we decided to use antegrade cerebral perfusion (ACP), retrograde cerebral perfusion (RCP) or no cerebral perfusion. Intraoperative cerebral oxygen testing was used to assess the effectiveness of intraoperative cerebral perfusion. When the value was below $20 \%$ of the baseline, we considered the cerebral perfusion to have had an effect and obtained additional measurements. For an expected arrest time of more than 30 minutes, the target value of cerebral temperature (Nasopharyngeal temperature) was $18-20^{\circ} \mathrm{C}$. For an arrest time of less than 30 minutes, the target value was $20-22^{\circ} \mathrm{C}$. Only a very small number of patients were assigned a cerebral temperature of $25^{\circ} \mathrm{C}$. In the ACP subgroup, before December 2015, we used an ACP perfusion rate of $6-10 \mathrm{~mL} / \mathrm{kg} / \mathrm{min}$. After January 2016, we have further reduced the flow rate to $3-5 \mathrm{~mL} / \mathrm{kg} / \mathrm{min}$.

\section{Statistical analysis}

Continuous variables are presented as the mean \pm standard deviation (after verifying the normality of the distribution of the data). Categorical variables are presented as absolute numbers and proportions. Data analysis was performed using SPSS 23 Statistics software (IBM, Herrenberg, Germany). Differences in categorical variables were analyzed using the $\chi^{2}$ test. Differences in continuous variables were tested using the $t$-test, or the Mann-Whitney $\mathrm{U}$ test, respectively. Multivariable analysis was performed using a binary logistic regression model to discriminate independent risk factors for 30-day mortality and CC. Kaplan-Meier survival analysis was used to compare the long-term follow-up survival rate between the non-CC and CC groups in terms of the odds ratio (OR) and the $95 \%$ confidence interval (CI). A value of $\mathrm{P}<0.05$ was considered statistically significant. In the propensity-score matching step, sex, age, and other preoperative characteristics were entered into a logistic regression model to estimate the propensity score. The best balance was reflected by a standardized difference below $10 \%$.

\section{Results}

\section{Comparable analysis between the non-CC and CC group}

The average age was $52.1 \pm 13.0$ years, and $75.9 \%$ of the patients were male. The mean body mass index (BMI) was $25.6 \pm 3.9\left(\mathrm{~kg} / \mathrm{m}^{2}\right)$. A total of 575 patients $(77.1 \%)$ had 
hypertension. Cerebral malperfusion was more common in the CC group (non-CC vs. CC, 9.6 vs. 40.0\%, $\mathrm{P}=0.000$ ). The ratio of permanent preoperative cerebral ischemic events was significantly higher in the $\mathrm{CC}$ group $(\mathrm{P}=0.001)$. According to the preoperative critical status, more patients in the CC group received emergent or salvage operations, although the difference with the non-CC group was not significant $(\mathrm{P}=0.060)$. The total average of operation time was $8.4 \pm 2.0$ hours, with cardiopulmonary bypass (CPB) and aortic clamp times of $247.3 \pm 83.6$ and $169.4 \pm 64.5$ minutes, respectively. The average time of hypothermic cerebral arrest (HCA) was different between the two groups (nonCC vs. CC, $29.3 \pm 12.0$ vs. $31.1 \pm 8.7$ minutes, $\mathrm{P}=0.036)$. CAR induced significantly lower rates of $\mathrm{CC}$. Access through the axillary artery had the lowest rate of CC. A total of $3.4 \%$ of patients with a low flow rate and $7.0 \%$ with a normal flow rate experienced $\mathrm{CC}(\mathrm{P}=0.035)$. The 30 -day mortality was $13.3 \%$ (99/746); patients in the CC group had significantly higher mortality than those in the non-CC group (nonCC vs. CC, $12.2 \%$ vs. $34.3 \%, \mathrm{P}=0.001$ ). The proportion of patients with prolonged mechanical ventilation was higher in the CC group (non-CC vs. CC, $18.3 \%$ vs. $37.1 \%$, $\mathrm{P}=0.006)$. A total of $1.5 \%$ patients of all patients developed paraplegia, which was more common in the CC group (nonCC vs. CC, $1.0 \%$ vs. $11.4 \%, \mathrm{P}=0.001)$. Other morbidities of common complications were nearly similar (Table 1).

In multivariable analysis, risk factors for mortality included age, tamponade, end-stage kidney disease (ESKD), operation time, salvage surgery, CC, extracorporeal membrane oxygenation (ECMO) support, continuous renal replacement therapy (CRRT) and re-intubation (Figure 1A). The independent risk factors for CC were preoperative cerebral ischemia, limb ischemia, ESKD, and salvage surgery (Figure 1B). Postoperative risk factors were paraplegia and mechanical ventilation. A low flow rate in ACP was a protective factor both for both mortality and $\mathrm{CC}$, and CAR acted as a protective factor for CC. After adjustment, CAR ( $\mathrm{P}=0.044$; odds ratio, 4.587; 95\% CI: 1.045-20.130) and a low flow rate in ACP $(\mathrm{P}=0.046$; odds ratio, 2.139; 95\% CI: $1.014-4.515)$ remained protective against $\mathrm{CC}$ (Table 2).

In the Kaplan-Meier survival analysis, we found that there were no differences between the non-CC and CC groups ( $\mathrm{P}=0.68$, Figure 2$)$.

\section{CAR: propensity-score matching analysis}

Three groups with 135 patients in each group were compared. Preoperative risk factors were consistent without differences. The times of CPB, X clamp and HCA were all significantly different. The CPB time was longer in total-arch group (non-arch $v s$. total-arch $v s$. archstent: $218.5 \pm 61.5$ vs. $265.3 \pm 90.0$ vs. $223.7 \pm 124.6$ minutes, $\mathrm{P}=0.000)$; similar observations were made for $\mathrm{X}$ clamp and HCA time. The morbidity rate for $\mathrm{CC}$ was higher in the Arch-stent group (non-arch vs. total-arch vs. arch-stent, $0.7 \%$ vs. $3.0 \%$ vs. $8.9 \%, \mathrm{P}=0.000)$, and the mortality rate was higher in the total-arch group (non-arch $v s$. total-arch vs. arch-stent, $9.6 \%$ vs. $17.0 \%$ vs. $11.9 \%, \mathrm{P}=0.175$ ) (Table 3).

\section{Low flow rate in ACP: propensity-score matching analysis}

Two separate groups of 148 patients each were compared. No differences were found in baseline demographic data, surgical methods, or intraoperative details. However, both the rate of $\mathrm{CC}$ and mortality were higher in the normal flow rate group (normal vs. low flow rate in ACP, CC: $10.8 \%$ vs. $5.4 \%$, $\mathrm{P}=0.067$; mortality: $19.6 \%$ vs. $8.8 \%, \mathrm{P}=0.012$ ) (Table 4).

\section{Discussion}

\section{Prevalence and risk factors}

TAAD is a lethal disease with high mortality and morbidity despite improvements in surgical techniques and organ protection methods. CC are the main complications after surgical repair for aortic dissection. In an STS database review, the operative mortality was $17 \%$, and the incidence of postoperative stroke was 13\% (3). The German registry for acute aortic dissection type A reported that the incidence of permanent neurological dysfunction (PND) was $13.4 \%$, the 30 -day mortality was $15.9 \%$, and PND patient mortality was $21.5 \%$ (2). The Japanese adult cardiovascular surgery database revealed a mortality of $6.1 \%$ and a stroke rate of $7.0 \%$ among all patients with total arch replacement, but the subgroup of aortic dissection comprised only $22.9 \%$ of the total (10). Wang and colleagues investigated the largest group from China, consisting of 1,708 patients with $57.8 \%$ of acute aortic dissection, and the overall PND rate was $4.8 \%$, with a mortality of $6.1 \%$ (11). Our single-center results were are nearly consistent with these results obtained from a patient database.

Preoperative cerebral ischemia has a strong relationship with postoperative $\mathrm{CC}$ and mortality, but the indications for emergent surgery for these patients are not clear. Of the 1,873 patients with type A dissection enrolled in IRAD, 87 
Table 1 Characteristics in patient with post operation cerebral complications (CC) and without that (non-CC) in a retrospective analysis

\begin{tabular}{|c|c|c|c|c|}
\hline Variable & Total $(\mathrm{N}=746)$ & Non-CC $(\mathrm{N}=711)$ & $\mathrm{CC}(\mathrm{N}=35)$ & $P$ value \\
\hline Age (years) & $52.1 \pm 13.0$ & $52.1 \pm 13.0$ & $52.4 \pm 10.9$ & 0.877 \\
\hline Gender (male), n (\%) & $566(75.9)$ & $538(75.7)$ & $28(80.0)$ & 0.362 \\
\hline $\mathrm{BMI}\left(\mathrm{kg} / \mathrm{m}^{2}\right)$ & $25.6 \pm 3.9$ & $25.5 \pm 3.9$ & $26.7 \pm 4.3$ & 0.648 \\
\hline Chronic & $62(8.3)$ & $60(8.4)$ & $2(5.7)$ & \\
\hline Hypertension, n (\%) & $575(77.1)$ & $523(73.6)$ & $25(71.4)$ & 0.456 \\
\hline Medicine control & $187(32.5)$ & $179(34.2)$ & $8(32.0)$ & 0.503 \\
\hline Marfan’s, n (\%) & $19(2.5)$ & $19(2.7)$ & $0(0.0)$ & 0.397 \\
\hline \multicolumn{5}{|l|}{ Previous cardiac surgery, $\mathrm{n}(\%)$} \\
\hline AVR/Bentall & $10(1.3)$ & $10(1.3)$ & $0(0.0)$ & 0.617 \\
\hline TEVAR/EVAR & $19(2.5)$ & $19(2.7)$ & $0(0.0)$ & 0.397 \\
\hline Previous coronary artery disease history, $\mathrm{n}(\%)$ & $19(2.5)$ & $19(2.7)$ & $0(0.0)$ & 0.397 \\
\hline ESKD, n (\%) & $12(1.6)$ & $10(1.4)$ & $2(5.7)$ & 0.105 \\
\hline Stroke history, n (\%) & $13(1.7)$ & $11(1.6)$ & $2(5.7)$ & 0.121 \\
\hline Tamponade, n (\%) & $118(15.8)$ & $111(15.6)$ & $7(20.0)$ & 0.310 \\
\hline Permanent & 10 & 4 & 6 & \\
\hline \multicolumn{5}{|l|}{ Operative characteristics } \\
\hline Surgical status, n (\%) & & & & 0.060 \\
\hline Salvage & $14(1.9)$ & $13(1.8)$ & $1(2.9)$ & \\
\hline Emergent & $457(76.4)$ & $426(59.9)$ & $31(88.6)$ & \\
\hline Elective & $162(21.7)$ & $159(22.4)$ & $3(8.6)$ & \\
\hline Operation time $(\mathrm{h})$ & $8.4 \pm 2.0$ & $8.4 \pm 2.0$ & $8.6 \pm 2.3$ & 0.471 \\
\hline CPB (min) & $247.3 \pm 83.6$ & $247.3 \pm 84.3$ & $248.0 \pm 69.2$ & 0.956 \\
\hline X clamp (min) & $169.4 \pm 64.5$ & $169.5 \pm 64.8$ & $166.9 \pm 59.9$ & 0.592 \\
\hline $\mathrm{DHCA}$ (min) & $29.4 \pm 11.8$ & $29.3 \pm 12.0$ & $31.1 \pm 8.7$ & 0.036 \\
\hline
\end{tabular}

Table 1 (continued) 
Table 1 (continued)

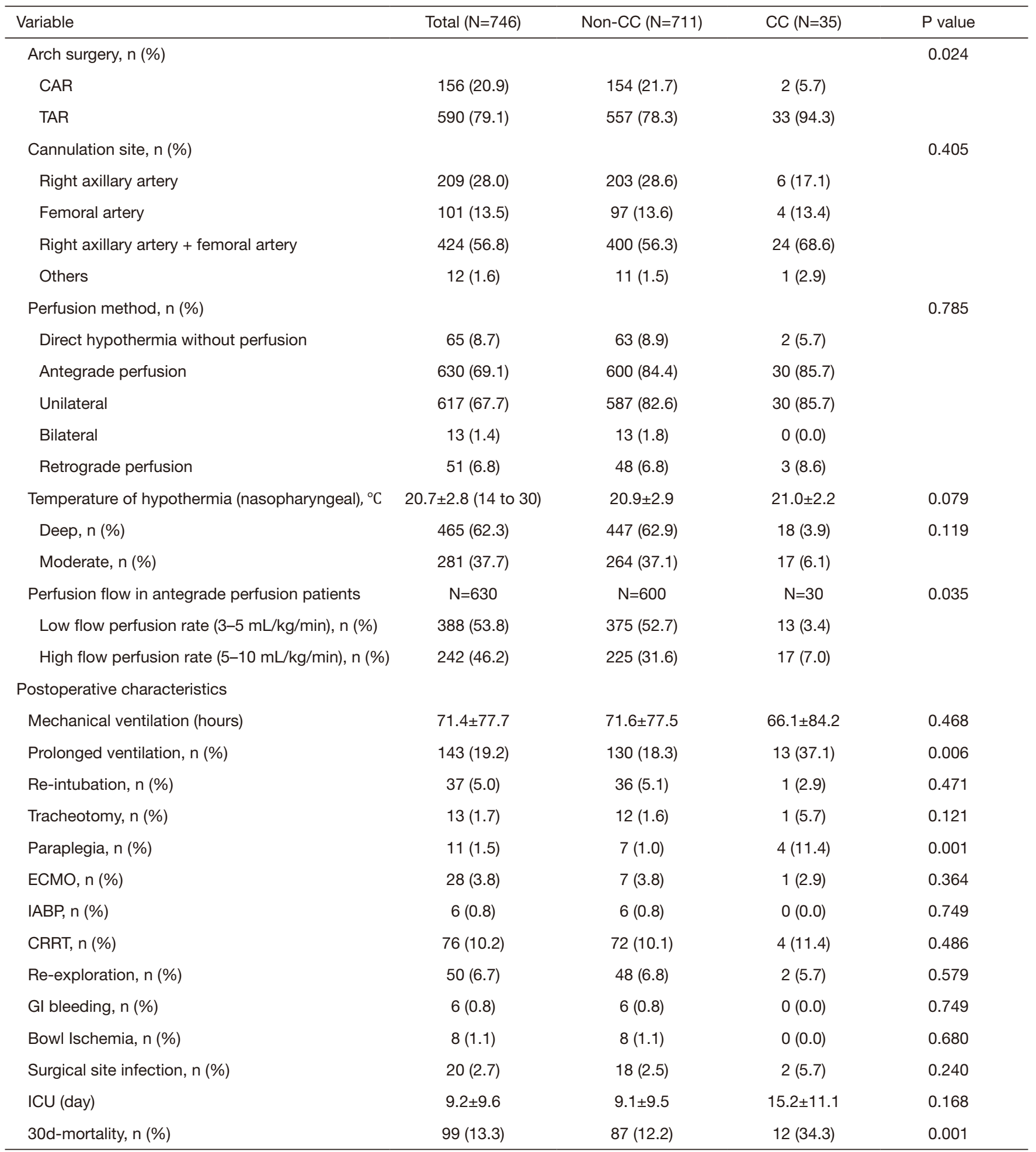

Dissection type: acute $\leq 2$ weeks, chronic $>2$ weeks. CC, cerebral complications; CAD, coronary artery disease; ESKD, end stage kidney disease; DHCA, deep hypothermia cardiac arrest; CABG, coronary artery bypass graft; MVR, mitral valve replacement; MVP, mitral valve plasty; TVP, mitral valve plasty; CAR, conservative arch replacement; TAR, total arch replacement; CRRT, continuous renal replacement therapy; GI, gastrointestinal; ICU, intensive care unit. 


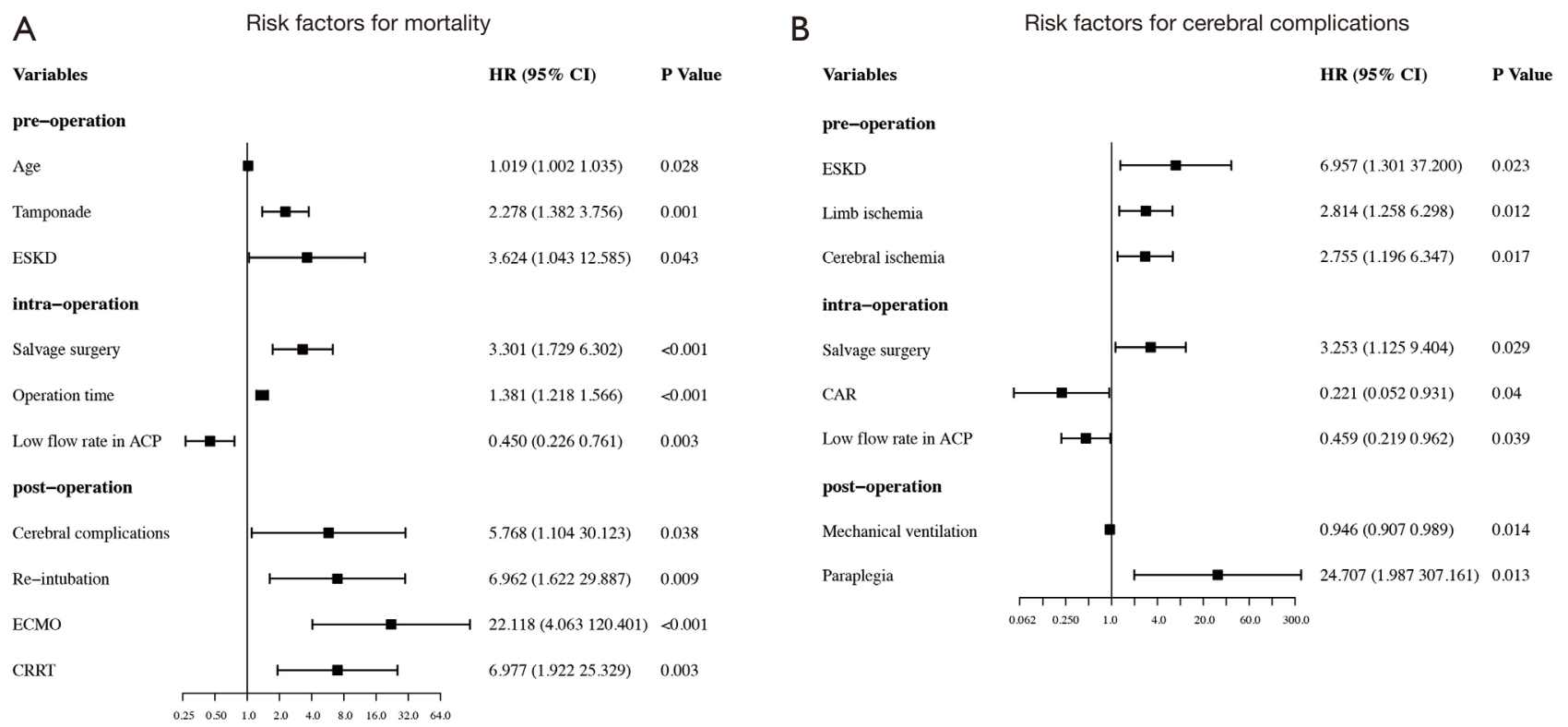

Figure 1 The results of the risk factors for postoperative CC and mortality from multivariate logistic regression analysis. (A) Risk factors for postoperative $\mathrm{CC}$ from multivariate logistic regression analysis; (B) risk factors for postoperative mortality from multivariate logistic regression analysis. CC, cerebral complications.

Table 2 Results of multivariable logistic regression of postoperative cerebral complications after adjustment

\begin{tabular}{lccc}
\hline Variable & OR & $95 \% \mathrm{Cl}$ & P value \\
\hline Age & 0.996 & $0.970-1.023$ & 0.771 \\
Gender (male) & 0.783 & $0.326-1.880$ & 0.584 \\
Cerebral ischemia & 0.153 & $0.071-0.327$ & 0.000 \\
Limb ischemia & 0.549 & $0.240-1.258$ & 0.156 \\
Salvage surgery & 0.338 & $0.149-1.011$ & 0.053 \\
CAR & 4.074 & $1.045-20.130$ & 0.044 \\
Low flow rate & 3.981 & $1.014-4.515$ & 0.046 \\
\hline
\end{tabular}

CAR, conservative arch replacement.

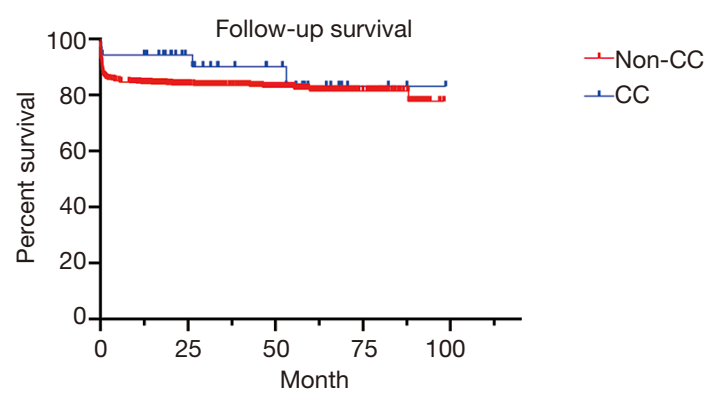

Figure 2 Follow-up results of comparing CC and non-CC patients. CC, cerebral complications.
(4.6\%) presented with cerebrovascular accidents, and 54 (2.9\%) presented with coma (12). In our experience, $11.0 \%$ $(82 / 746)$ of patients had preoperative cerebral ischemia, and only $1.3 \%$ had preoperative PND. Among them, 14 patients developed CC after surgery, 6 of them with PND before surgery. IRAD found that surgery led to a hospital survival benefit of $49.6 \%$ in patients with preoperative neurologic symptoms and $55.6 \%$ in those with coma (12). Therefore, we must continue to attempt surgical repair first for these patients with cerebral ischemia.

\section{Brain protections methods: conservative arch repair}

In addition to preoperative cerebral ischemia including $\mathrm{CC}$ after surgical repair for TAAD, intraoperative brain protection methods are the key factors impacting cerebral outcomes. Ghoreishi listed cannulation strategy, degree of hypothermia, cerebral perfusion method and techniques for arch repair as the main factors that could impact postoperative cerebral complication (3). Among them, hemiarch surgery was shown to play a protective role for the brain. We identified CAR as having a lower rate of CC and mortality than TAR in both the retrospective analysis and propensity-score matching analysis. However, our results are inconsistent with those from retrospective reviews. Rice 
Table 3 Among different arch methods group in a perspective study

\begin{tabular}{|c|c|c|c|c|}
\hline Variable & CAR $(N=135)$ & \multicolumn{2}{|c|}{ TAR, n (\%) } & $P$ value \\
\hline Cerebral complications, n (\%) & $1(0.7)$ & $4(3.0)$ & $11(8.9)$ & 0.005 \\
\hline Mortality, n (\%) & $13(9.6)$ & $23(17.0)$ & $16(11.9)$ & 0.175 \\
\hline Age, years & $55.7 \pm 14.2$ & $49.8 \pm 11.8$ & $53.3 \pm 13.2$ & 0.429 \\
\hline Limb ischemia, $\mathrm{n}(\%)$ & $12(32.4)$ & $13(35.1)$ & $12(32.4)$ & 0.971 \\
\hline ESKD, n (\%) & $2(1.9)$ & $4(1.9)$ & $2(0.9)$ & 0.600 \\
\hline Tamponade, n (\%) & $29(26.3)$ & $31(12.3)$ & $29(14.4)$ & 0.944 \\
\hline Surgery status (emergency surgery), $\mathrm{n}(\%)$ & $107(80.1)$ & $96(76.6)$ & $106(79.4)$ & 0.220 \\
\hline $\mathrm{DHCA}(\mathrm{min})$ & $28.3 \pm 9.7$ & $33.9 \pm 9.0$ & $24.9 \pm 8.6$ & 0.000 \\
\hline Mechanical ventilation (hours) & $41.1 \pm 48.1$ & $82.5 \pm 92.4$ & $57.3 \pm 60.7$ & 0.000 \\
\hline ICU (day) & $3.7 \pm 4.1$ & $8.0 \pm 10.4$ & $4.5 \pm 6.1$ & 0.000 \\
\hline
\end{tabular}

Arch stent: including tripled branched arch stent, single branched arch stent and fenestrated arch stent. CAR, conservative arch replacement; TAR, total arch replacement; ESKD, end stage kidney disease; CPB, cardiopulmonary bypass; DHCA, deep hypothermia cardiac arrest; ICU, intensive care unit;

Table 4 Low and high flow rate in ACP in a perspective study

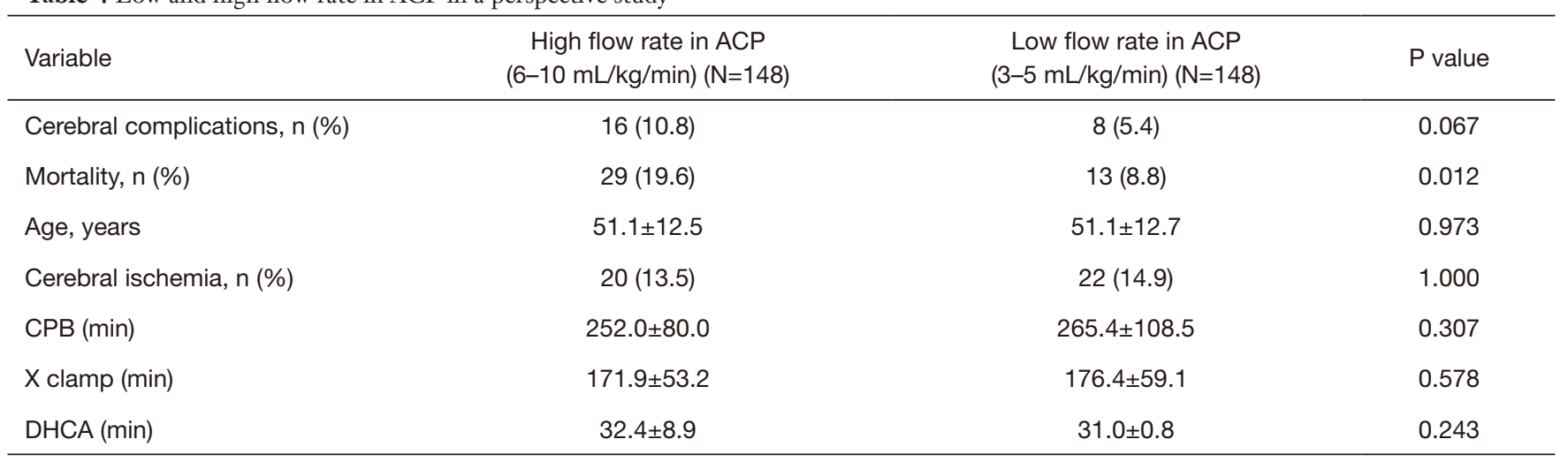

CPB, cardiopulmonary bypass; DHCA, deep hypothermia cardiac arrest; ACP, antegrade cerebral perfusion.

et al. studied 489 patients who underwent TAAD surgery, and the rate of stroke was not significantly different between the total arch group (8.2\%) and the hemiarch group (10.5\%) (13). Rylski et al. also found similar neurological outcomes in a cohort, but TAR was a strong predictor for mortality (14). However, Roselli et al. found that the rate of reintervention for patients with hemiarch repair was $38 \%$ within 10 years, which suggested more aggressive techniques for arch repair in TAAD (15). In the present study, TAR included arch surgery with arch stents, as described in previous studies $(5,6)$. Arch stents are used to simplify the arch surgery and achieve a reshaping effect with the frozen elephant trunk technique. However, the rate of CC was higher than that of the total arch and CAR groups, while the mortality was lower than that of the total arch group and similar to that of the CAR group. One possible reason for these differences was that the underestimation of the incidence of CC in the case of high 
mortality in the total arch group. Another was that arch manipulation could not be avoided during the arch stent procedure. During the HCA period, we had to clamp the innominate artery and left common carotid artery, then insert the arch stent system and release it in anatomical proximity to the proximal artificial vessel. Arterial clamping injury and the potential risk for blood flow from a new stent in the arch position are all possible origins of thrombi and low perfusion, respectively. We considered the possibility of aggressive arch repair to reduce the rate of reintervention, but the method of arch stent repair still has limitations and disadvantages for brain protection based on our results. Investigating the indications and optimizing the surgical manipulations are necessary in future studies.

\section{Brain protection methods: cerebral perfusion and flow rate}

In our series, we used different perfusion methods, including direct HCA without perfusion, ACP and RCP, but all had similar rates of CC. HCA is a basic method for aortic arch surgery where body temperature is lowered to preserve organ function and reduce metabolic demand (16). The safety duration of HCA ranges between 25-60 min. The researchers found that an HCA duration longer than 40 minutes will increase the risk of postoperative CC and mortality (17). Despite the safe duration, direct HCA have revealed similar risk for CC. Ghoreishi et al. found that $29 \%$ of patients in their cohort had not received an adjunct technique for cerebral perfusion, but it was not found to be a risk factor for postoperative stroke (3). However, in our series, the average time for HCA in the TAR group was longer than 30 minutes, which meant for most patients with HCA, no cerebral perfusion was exposed to damage caused by a prolonged HCA time. This is why adjunct methods are necessary. ACP is widely used and can be physiologically adapted when the duration of ACP is longer (18-21). Keeling et al. retrospectively reviewed 342 patients using moderate hypothermic circulatory arrest and selective ACP. The median circulatory arrest time was 38.9 minutes, the mortality was $11.7 \%$, and the rate of PND was $7.3 \%$ (19). In a propensity-score matching analysis consisting of 925 elective aortic arch surgery patients with ACP or HCA alone, the mortality and PND rates were all significantly lower in the ACP group (3.8\% and 2.9\%, respectively) (21). However, no results on the superiority of ACP in TAAD arch surgery have been confirmed. Angleitner et al. reported on both unilateral and bilateral ACP for TAAD arch surgery. During the average HCA time of 34 minutes, the rate of PND was $19.0 \%$, and the mortality rate was $14.1 \%$ (22). This perplexed us in the early stage after the burden of ischemia resolved with the aid of adjunct ACP. The concepts regarding direct HCA and the clinical findings of facial edema after ACP + HCA surgery inspired us to also consider the burden of luxury-over perfusion from ACP. Autoregulation of cerebral circulation is the key physiological function for maintaining the related normal flow for the brain $(23,24)$. However, cerebral autoregulation can become dysfunctional when the body cools to temperatures lower than $22^{\circ} \mathrm{C}$. This means that the resistance of cerebral vessels will not increase to adapt to ischemia, and the blood flow of the cerebral circulation will increase, which may be a potential risk factor for increased intracerebral pressures, cerebral edema, and microvascular damage. The weight of normal human adult brain is $1.5 \%$ to $3.0 \%$ of that of the whole body, and the normal physiological cerebral blood flow is $55 \mathrm{~mL} / \mathrm{min} / 100 \mathrm{~g}$ of cerebral matter. This means that a blood flow of nearly $8-16 \mathrm{~mL} / \mathrm{kg} / \mathrm{min}$ is necessary at baseline of physiological demand. However, when the temperature decreases, the physiological demand also decrease, reaching is nearly $30 \%$ of the baseline at $22{ }^{\circ} \mathrm{C}(25)$. Therefore, we chose $3-$ $5 \mathrm{~mL} / \mathrm{kg} / \mathrm{min}$ as the perfusion flow rate.

An animal model was used to show that a higher perfusion rate in ACP can not only improve cerebral perfusion to improve metabolism, but also cause intracranial edema (26). No clinical trials can be performed to compare the different flow rates applied for ACP for ethical reasons, but the clinical experiences from our center present new proof of the benefit of a low flow rate for ACP. We used NIRS to detect the cerebral metabolism and adjusted the flow rate based on the baseline value and variated value.

\section{Limitations}

This article is a retrospective analysis from a single center. Even with a large cohort of cases, the bias of such a study design cannot be ignored. We attempted to adjust for the preoperative factors in two separated propensityscore matching analyses, but the missing data during this processaffeced the real results. Otherwise, TAAD is primarily emergent or urgent surgery, which we cannot compare factors in an RCT. The data from our single center 
reflect the results from a real-world experience.

\section{Conclusions}

In conclusion, our single-center results for TAAD repair, including a mortality of $13.3 \%$ and rate of CC of $4.7 \%$ were interesting. Preoperative status remained the key factor inducing mortality and adverse cerebral outcomes. Conservative arch repair had lower mortality and morbidity than total arch repair for TAAD, but considering the necessity of TAR, the technique also achieved acceptable results. Low flow rate in ACP may be a safer and potentially better technique for cerebral protection, but it must be compared with traditional methods in the further prospective studies.

\section{Acknowledgments}

Funding: This work has been supported by the National Key R\&D program of China (2016YFC1000808), National Natural Science Foundation of China (No. 81970401, No. 81670437) and Jiangsu Provincial Key Medical Discipline (ZDXKA2016019).

\section{Footnote}

Reporting Checklist: The authors have completed the STROBE reporting checklist. Available at https://dx.doi. org/10.21037/apm-20-2365

Data Sharing Statement: Available at https://dx.doi. org/10.21037/apm-20-2365

Conflicts of Interest: All authors have completed the ICMJE uniform disclosure form (available at https://dx.doi. org/10.21037/apm-20-2365). The authors have no conflicts of interest to declare.

Ethical Statement: The authors are accountable for all aspects of the work in ensuring that questions related to the accuracy or integrity of any part of the work are appropriately investigated and resolved. We retrieved the data retrospectively by a review of hospital records, and individual consent for this retrospective analysis was waived. The study was conducted in accordance with the Declaration of Helsinki (as revised in 2013). The study was approved by the Institutional Review Board of Nanjing Drum Tower Hospital (No. 2020-185-01).
Open Access Statement: This is an Open Access article distributed in accordance with the Creative Commons Attribution-NonCommercial-NoDerivs 4.0 International License (CC BY-NC-ND 4.0), which permits the noncommercial replication and distribution of the article with the strict proviso that no changes or edits are made and the original work is properly cited (including links to both the formal publication through the relevant DOI and the license). See: https://creativecommons.org/licenses/by-nc-nd/4.0/.

\section{References}

1. Dumfarth J, Kofler M, Stastny L, et al. Stroke after emergent surgery for acute type A aortic dissection: predictors, outcome and neurological recovery. Eur J Cardiothorac Surg 2018;53:1013-20.

2. Kruger T, Weigang E, Hoffmann I, et al. Cerebral protection during surgery for acute aortic dissection type A: results of the German Registry for Acute Aortic Dissection Type A (GERAADA). Circulation 2011;124:434-43.

3. Ghoreishi M, Sundt TM, Cameron DE, et al. Factors associated with acute stroke after type A aortic dissection repair: An analysis of the Society of Thoracic Surgeons National Adult Cardiac Surgery Database. J Thorac Cardiovasc Surg 2020;159:2143-54.e3.

4. Ergin MA, Galla JD, Lansman s L, et al. Hypothermic circulatory arrest in operations on the thoracic aorta. Determinants of operative mortality and neurologic outcome. J Thorac Cardiovasc Surg 1994;107:788-97; discussion 797-9.

5. Pan J, Li QG, Zhou Q, et al. Repair of acute type A aortic dissections using open replacement with triple-branched stent grafts. Ann Thorac Surg 2013;96:559-62.

6. Zhou Q, Xue Y, Cao H, et al. Novel arch fenestrated stent graft for acute Stanford Type A aortic dissection with open antegrade implantation. Interact Cardiovasc Thorac Surg 2018;26:369-75.

7. Xue Y, Pan J, Cao H, et al. Different aortic arch surgery methods for type A aortic dissection: clinical outcomes and follow-up results. Interact Cardiovasc Thorac Surg 2020;31:254-62.

8. Xue Y, Zhou Q, Pan J, et al. Root reconstruction for proximal repair in acute type A aortic dissection. Journal of Thoracic Disease 2019;11:4708-16.

9. Xue Y, Zhou Q, Pan J, et al. "Double Jacket Wrapping" Root Reconstruction for Acute Type A Aortic Dissection. Ann Thorac Surg 2020;110:1060-2.

10. Okita $\mathrm{Y}$, Miyata $\mathrm{H}$, Motomura N, et al. A study of brain 
protection during total arch replacement comparing antegrade cerebral perfusion versus hypothermic circulatory arrest, with or without retrograde cerebral perfusion: analysis based on the Japan Adult Cardiovascular Surgery Database. J Thorac Cardiovasc Surg 2015;149:S65-73.

11. Wang X, Yang F, Zhu J, et al. Aortic arch surgery with hypothermic circulatory arrest and unilateral antegrade cerebral perfusion: Perioperative outcomes. J Thorac Cardiovasc Surg 2020;159:374-87.e4.

12. Di Eusanio M, Patel HJ, Nienaber CA, et al. Patients with type A acute aortic dissection presenting with major brain injury: should we operate on them? J Thorac Cardiovasc Surg 2013;145:S213-21.e1.

13. Rice RD, Sandhu HK, Leake SS, et al. Is Total Arch Replacement Associated With Worse Outcomes During Repair of Acute Type A Aortic Dissection? Ann Thorac Surg 2015;100:2159-65; discussion 2165-6.

14. Rylski B, Beyersdorf F, Kari FA, et al. Acute type A aortic dissection extending beyond ascending aorta: Limited or extensive distal repair. J Thorac Cardiovasc Surg 2014;148:949-54; discussion 954.

15. Roselli EE, Loor G, He J, et al. Distal aortic interventions after repair of ascending dissection: the argument for a more aggressive approach. J Thorac Cardiovasc Surg 2015;149:S117-24.e3.

16. Griepp RB, Stinson EB, Hollingsworth JF, et al. Prosthetic replacement of the aortic arch. J Thorac Cardiovasc Surg 1975;70:1051-63.

17. Ganapathi AM, Hanna JM, Schechter MA, et al. Antegrade versus retrograde cerebral perfusion for hemiarch replacement with deep hypothermic circulatory arrest: does it matter? A propensity-matched analysis. J Thorac Cardiovasc Surg 2014;148:2896-902.

Cite this article as: Xue Y, Liu C, Mi L, Chen Y, Wang D. Risk factors for cerebral complications after type A aortic dissection surgery: single center's experience. Ann Palliat Med 2021;10(7):7458-7467. doi: 10.21037/apm-20-2365
18. Comas GM, Leshnower BG, Halkos ME, et al. Acute type a dissection: impact of antegrade cerebral perfusion under moderate hypothermia. Ann Thorac Surg 2013;96:2135-41.

19. Keeling WB, Leshnower BG, Hunting JC, et al. Hypothermia and Selective Antegrade Cerebral Perfusion Is Safe for Arch Repair in Type A Dissection. Ann Thorac Surg 2017;104:767-72.

20. Urbanski PP, Luehr M, Di Bartolomeo R, et al. Multicentre analysis of current strategies and outcomes in open aortic arch surgery: heterogeneity is still an issue. Eur J Cardiothorac Surg 2016;50:249-55.

21. Leontyev S, Davierwala PM, Semenov M, et al. Antegrade selective cerebral perfusion reduced in-hospital mortality and permanent focal neurological deficit in patients with elective aortic arch surgerydagger. Eur J Cardiothorac Surg 2019;56:1001-8.

22. Angleitner P, Stelzmueller ME, Mahr S, et al. Bilateral or unilateral antegrade cerebral perfusion during surgery for acute type A dissection. J Thorac Cardiovasc Surg 2020;159:2159-67.e2.

23. Bachet J. Re: Selective cerebral perfusion using moderate flow in complex cardiac surgery provides sufficient neuroprotection. Are children young adults? Eur J Cardiothorac Surg 2012;42:710-1.

24. Lassen NA. Cerebral blood flow and oxygen consumption in man. Physiol Rev 1959;39:183-238.

25. Ehrlich MP, McCullough JN, Zhang N, et al. Effect of hypothermia on cerebral blood flow and metabolism in the pig. Ann Thorac Surg 2002;73:191-7.

26. Haldenwang PL, Strauch JT, Amann I, et al. Impact of pump flow rate during selective cerebral perfusion on cerebral hemodynamics and metabolism. Ann Thorac Surg 2010;90:1975-84. 